\title{
Factors associated with household food insecurity and depression in pregnant South African women from a low socio-economic setting: a cross-sectional study
}

\author{
Zulfa Abrahams $^{1}$ (D) Crick Lund $^{2,3} \cdot$ Sally Field ${ }^{1} \cdot$ Simone Honikman ${ }^{1}$
}

Received: 8 December 2017 / Accepted: 2 February 2018 / Published online: 14 February 2018

(c) The Author(s) 2018. This article is an open access publication

\begin{abstract}
Purpose Food insecurity has been linked with maternal depression in low-income settings. Few studies have looked at factors associated with both food insecurity and maternal depression as outcomes. This study aimed to assess factors associated with food insecurity and depression in a sample of pregnant South African women.

Methods We conducted a cross-sectional study at a Midwife Obstetric Unit in a low-income suburb in Cape Town. Pregnant women attending the clinic for their first antenatal visit were invited to participate. The shortened form of the US Household Food Security Survey Module was used to measure food insecurity. The Expanded Mini-International Neuropsychiatric Interview was used to diagnose depression, anxiety, alcohol and drug dependence, and assess for suicidal ideation and behaviour. Logistic regression modelling was conducted to explore factors associated with food insecurity and depression in separate models.

Results We found that $42 \%$ of households were food insecure and that $21 \%$ of participants were depressed $(N=376)$. The odds of being food insecure were increased in women with suicidal behaviour ( $\mathrm{OR}=5.34$; 95\% CI 1.26-22.57), with depression $(4.27 ; 1.43-12.70)$ and in those with three or more children $(3.79 ; 1.25-11.55)$. The odds of depression was greater in women who were food insecure $(5.30 ; 1.63-17.30)$, substance dependent $(15.83 ; 1.31-191.48)$ or diagnosed with an anxiety disorder (5.04; 1.71-14.82).

Conclusions Food insecurity and depression are strongly associated in pregnant women. The relationship between food insecurity and depression is complex and requires further investigation. Interventions that improve both food security and mental health during the perinatal period are likely to benefit the physical and mental well-being of mothers and children.
\end{abstract}

Keywords Food insecurity $\cdot$ Depression $\cdot$ Anxiety $\cdot$ Suicidality $\cdot$ Low-resource settings $\cdot$ Pregnant

\section{Introduction}

Zulfa Abrahams

zulfa.abrahams@uct.ac.za

1 Department of Psychiatry and Mental Health, Perinatal Mental Health Project, Alan J Flisher Centre for Public Mental Health, University of Cape Town, Building B, 46 Sawkins Road, Rondebosch, Cape Town 7700, South Africa

2 Centre for Global Mental Health, Institute of Psychiatry, Psychology and Neuroscience, King's College London, London, UK

3 Department of Psychiatry and Mental Health, Alan J Flisher Centre for Public Mental Health, University of Cape Town, Cape Town, South Africa
Despite the political and economic advances made in South Africa since achieving democracy in 1994, many South Africans continue to experience poverty and unemployment [1]. In a recent poverty report by Statistics South Africa [2], 30.4 million South Africans (55.5\% of the population) were estimated to be living below the upper-bound poverty line, which is less than 992 South African Rands (ZAR992) or US $\$ 81.93$ per person per month ( $\mathrm{pppm}$ ). South Africans living above the upper-bound poverty line are able to purchase both adequate levels of food and non-food items to ensure adequate health.

One of the key aspects of poverty is the inability to provide adequately for the households' food needs. Food security is defined by the Food and Agriculture Organisation of 
the United States [3] as 'a situation that exists when all people, at all times, have physical, social and economic access to sufficient, safe and nutritious food that meets their dietary needs and food preferences for an active and healthy life'. On the other hand, food insecurity exists when the availability of nutritionally adequate and safe foods, or the ability to acquire acceptable foods in an acceptable way, is limited or uncertain [4].

The food poverty line (FPL), is defined as the South African Rand value below which individuals are unable to purchase or consume enough food to supply them with the minimum per-capita-per-day energy requirements for adequate health [2], and is used to estimate the number of people living in extreme poverty. In South Africa, based on 2015 prices, the FPL was equivalent to R441 (US\$36.42) pppm. In 2015, 25.2\% of South Africans were living below the FPL, and were thus considered to be food insecure [2]. In addition, $41 \%$ of South African households are headed by women [1], giving women the decision making power, as well as the responsibility of being the breadwinner. During the perinatal period, women may be economically vulnerable, as their income-generating potential may have reduced, and their financial needs, such as having to eat well, attending regular clinic visits and providing childcare are likely to increase [5].

Research from low-income settings, including from within South Africa, shows that mental illness is associated with greater poverty, worse health, stressful interpersonal relationships and informal or no employment [6, 7]. During the perinatal period, the prevalence of depression is increased, particularly in low- and middle-income countries (LMIC) [8, 9].

Maternal depression is highly prevalent in low-income settings [8-11], and is associated with food insecurity [12-14]. Moreover, food insecurity is a strong predictor of maternal depression [15], while depression in mothers in low-income settings has been found to be a strong predictor of household food insecurity [16]. Patel [17] suggests that poverty and mental illness interact in a vicious cycle, whereby the risk of mental distress is increased in those living in poverty as a result of reduced social capital, social exclusion, violence and trauma, and poor access to health care. In turn, those with a mental illness are at an increased risk of poverty as a result of increased health expenses, lost employment, poor social support and stigma which surrounds mental illness [18]. While studies from LMICs such as Ethiopia [14, 19] and South Africa [15] have found that food insecurity is a strong predictor of maternal depression, studies showing that maternal depression predicts food insecurity were primarily in high-income countries such as Britain [16] and the USA [20]. Few studies [21] have looked at factors associated with both food insecurity and maternal depression as outcomes. Conducting these analyses in LMIC is important to understand more about the complex bidirectional relationship between food insecurity and depression. We hypothesised that, for pregnant women living in adverse settings, the poverty-mental illness cycle would be particularly prevalent. Therefore, this study aimed to use multivariate regression analysis to assess predictors of food insecurity and depression in a sample of pregnant women living in a low socio-economic setting in South Africa.

\section{Methods}

\section{Participants}

This cross-sectional study was conducted at the Hanover Park Midwife Obstetric Unit (MOU), in Cape Town, South Africa. Hanover Park is a low-income, residential suburb within the City of Cape Town, established in 1969 as part of the South African Apartheid governments Group Areas Act [22]. It has a population of approximately 45,000 people and experiences widespread gang activity and high rates of violent crimes. Coupled with this are numerous social problems such as school drop-outs, drug and alcohol abuse, prostitution, drug trafficking, and robberies. Education levels are low and unemployment is high. Only $21 \%$ of the residents have passed high school, while $36 \%$ are unemployed [23].

Every third woman, 18 years or older, attending the MOU for her first antenatal clinic visit, was invited to participate in the study between November 2011 and August 2012. Of the 559 eligible women who were invited to participate, 135 (24\%) declined to participate, and 376 women were recruited. As the process was relatively time consuming, 48 women were not able to take the time to complete the questionnaires, due to work or childcare commitments.

\section{Testing procedures}

An interviewer-administered socio-demographic questionnaire was used to collect data on participants' age, obstetric information and feelings about pregnancy, level of education, relationship status, HIV status, socio-economic status, and prior experience of depression or anxiety.

Screening tools were selected based on either local validation data or their having been used in other resource constrained settings. The US Household Food Security Survey Module (HFSSM): 6-Item Short Form [4] was used to assess household food insecurity and hunger. The scale measures the frequency of running out of food, being unable to afford balanced meals, and skipping meals because of lack of food over the prior 6 months. Perceptions of social support from three possible sources (family, friends and a significant other) were measured using the Multidimensional Scale of 
Perceived Social Support (MSPSS) [24]. Threatening life experiences faced by women in the preceding 6 months were measured using the List of Threatening Experiences (LTE) [25]. The Revised Conflict Tactic Scales (CTS2) [26] was used to measure Intimate partner violence.

The Expanded Mini-International Neuropsychiatric Interview (MINI Plus) Version 5.0.0 [27, 28], was used to diagnose a major depressive episode (MDE) (Module A), generalised anxiety disorder (Module P), suicidality (Module $\mathrm{C}$ ), alcohol dependence (Module $\mathrm{K}$ ) and substance dependence (Module $\mathrm{L}$ ), and has been validated in several countries, including South Africa [29-31]. The MINI was administered by an experienced, registered counsellor, who was supervised by a clinical psychologist. The MINI Plus is available in local South African languages-Afrikaans and isiXhosa [32]. All tools were administered in English, Afrikaans or isiXhosa, the languages spoken by the women attending the MOU.

Participants were provided with refreshments mid-way through the interview process. Participants were not provided with money for participation or transport. The testing procedures are explained in more detail published elsewhere [33].

\section{Ethical approval}

Ethical approval for the study was obtained from the Human Research and Ethics Committee at the University of Cape Town (HREC REF: 131/2009). The Western Cape provincial Department of Health approved the use of the research site. All respondents who participated in the study provided written, informed consent after the procedure had been verbally explained to them. Consent forms were available in English, Afrikaans and isiXhosa. All those participants who were diagnosed with a mental disorder were offered on-site, free of charge counselling with a registered counsellor.

\section{Data analysis}

Data analysis was carried out using STATA/SE statistical software package version 14.1 (StataCorp., College Station, TX, USA). Variables were described using frequency and percentages, and associations measured using Chi-square tests. An asset index was used to stratify households based on socio-economic status [34]. Asset indices have previously been used in studies in LMICs [35, 36]. To construct the asset index, information on ownership of electronic equipment (e.g., fridge or freezer, vacuum cleaner, television, microwave, washing machine, television), transport (owning a vehicle), sources of energy (electricity) and bank accounts (including credit card) were pooled together. Principal component analysis was used to stratify households into 4 quartiles representing least poor, poor, very poor and poorest.

The nine questions comprising Module C of the MINI Plus were used to develop three categories of suicidality based on experiences in the month prior to the interview. Suicidal ideation included questions on suicidal thoughts (questions c2-c4). Suicidal behaviour included questions on plans to commit suicide as well as suicide attempts (questions $\mathrm{c5-c8)}$. Suicidal ideation and behaviour referred to those who endorsed items pertaining to suicidal thoughts, and those who endorsed items pertaining to planning, preparing or attempting suicide (questions $\mathrm{c} 2-\mathrm{c} 8$ ).

The primary outcome variables in the regression analyses were; (1) food insecurity and (2) MDE. Currently there is no accepted measure or standardised way of measuring food insecurity in South Africa. The cut-points suggested in the user notes of the 6-item short form of the US Household Food Security Module [37] were used: a score of 0-1 indicates high or marginal food security; a score of 2-4 indicates low food security; a score of 5-6 indicates very low food security. We assigned food security status as follows: households with a score of $0-1$ are referred to as food secure, while households with a score of 2-6 [derived by combining low food security (score of 2-4) and very low food security (score of 5-6)] are referred to as food insecure. MDE was diagnosed using Module A of the MINI Plus.

Model building techniques were used to develop multivariate logistic regression models for food insecurity and MDE separately. We controlled/adjusted for the following extraneous variables so as to exclude their effect on the outcome variable: participant income, household income, employment status, number of children, having an unplanned pregnancy, and feeling happy about the pregnancy. Univariate analysis was used to identify significant associations between food insecurity and a number of correlates. The following correlates, which were significantly associated with food insecurity, were then used to build the final multivariate model: participants' income, employment status, household income, number of children, suicidal behaviour, MDE, anxiety disorder, history of mental illness, experience of a threatening life event in the past year, experiencing intimate partner violence, perceived social support, substance dependence and alcohol dependence.

In the second model, univariate analysis was used to identify significant associations between MDE and a number of correlates. The following correlates, which were significantly associated with MDE, were then used to build the final multivariate model: household income, number of children, unplanned pregnancy, feeling happy about pregnancy, substance dependence, anxiety disorder, food insecurity, experience of intimate partner violence, perceived social support, experience of a threatening life event in the past 
year, suicidal ideation and behaviour, history of mental illness, and alcohol dependence.

\section{Results}

Participant characteristics are presented in Table 1. The study sample consisted of 376 pregnant women, of whom $158(42 \%)$ were food insecure, $81(21.4 \%)$ were diagnosed with MDE and 86 (22.8\%) were diagnosed with anxiety disorder. Of those who were diagnosed with an MDE, 37\% reported having a history of mental illness. Significantly more women who were food insecure had $>4$ pregnancies $(p=0.005),>3$ children $(p<0.001)$, less education $(p=0.021)$, and less income $(p=0.049)$. More women who were food insecure had a history of mental illness (61.4 vs. $38.6 \%$; $p=0.001)$, had experienced a threatening life event (58.2 vs. $41.8 \% ; p<0.001)$, and had been exposed to intimate partner violence (62.1 vs. $37.9 \% ; p=0.001$ ), compared to those who were food secure.

Table 2 provides an overview of the six questions making up the HFSSM, and the number and proportion of households with positive answers to the questions. In 53\% of households, the food that was bought did not last and there was not any money for more, while in almost half the homes (45\%) household members couldn't afford to eat balanced meals.

Bivariate associations between food security status and common mental disorders and substance and alcohol dependence are shown in Table 3. Food insecurity was significantly associated with a diagnosis of MDE $(p<0.001)$, an anxiety disorder $(p<0.001)$, suicidal behaviour $(p=0.011)$, alcohol $(p=0.021)$ and substance dependence $(p=0.048)$.

The odds of food insecurity in pregnant women are shown in Table 4. In the full multivariate model, the odds of being food insecure was more than five times greater in women with suicidal behaviour [OR $=5.34(1.26-22.5)$; $p=0.023]$, more than four times greater in women with a MDE [OR $=4.27$ (1.43-12.70); $p=0.009$ ], and almost four times greater in women with three or more children [OR $=3.79(1.25-11.55) ; p=0.019]$, when compared to women who are food secure. This model was able to correctly classify $74.2 \%$ of participants.

The odds of having a MDE are shown in Table 5. In the full multivariate model, the odds of having a diagnosis of MDE was more than 15 times greater in women with substance dependence [OR $=15.83(1.31-191.48) ; p=0.030]$, five times greater in women with anxiety disorder [5.04 (1.71-14.82); $p=0.003$ ], more than five times greater in women who were food insecure [5.30 (1.63-17.30); $p=0.006]$, and decreased with increasing perceived social support [0.95 (0.92-0.98); 0.003]. This model was able to correctly classify $88.7 \%$ of participants.

\section{Discussion}

In this cross-sectional study of pregnant South African women living in an urban, low socio-economic setting, we found that $42 \%$ of households were food insecure, and that $21 \%$ of participants were depressed. The bivariate analysis showed that food insecurity was significantly associated with all MINI-diagnosed disorders, except suicidal ideation. Using multiple logistic regression analysis, we found that the odds of being food insecure was increased in women with suicidal behaviour, with depression and in those with three or more children. In addition, we found that the odds of experiencing a MDE was greater in women who were food insecure, substance dependent or diagnosed with an anxiety disorder.

The 2016 Community Survey by Statistics South Africa [1] reported that $20 \%$ of South African households ran out of money to buy food in the past 12 months. Our study reported a much higher prevalence. In Hanover Park, 53\% of pregnant women attending the MOU reported running out of food and not having any money to buy more. This high prevalence is not completely unexpected as Hanover Park is known for its high rates of poverty, unemployment and gangsterism [38], and food insecurity is a well-documented consequence of poverty and unemployment [39]. The relationship between poverty and food insecurity is complex and considered to operate in a vicious cycle. While poverty leads to hunger and lack of adequate nutrition; hunger and malnutrition decreases the ability to learn, work and adequately care for the family—all of which perpetuate poverty [40].

The association between poverty and common mental illnesses, as well as between food insecurity and common mental illnesses in LMIC are well-documented in systematic reviews $[8,41]$. However, the size and direction of the association varies in different populations and by different measures of food insecurity and mental illness. In Equador, self-reported symptoms of depression in mothers increased the risk of the household being food insecure by almost three times [42], while the risk of food insecurity in Korean adults who reported feelings of sadness and despair were almost four times greater than in those who did not report feeling sadness and despair [43]. We found that the risk of being food insecure was 4.3 times greater in pregnant women who were diagnosed with depression, compared to those who were not depressed. This is much higher than the $8 \%$ increased risk of food insecurity that Pellowski et al. [44] reported, and the 5\% increased risk that Dewing et al. [29] reported. While both studies took place in urban settings in South Africa, and used the EPDS to measure depression, 
Table 1 Demographic and social characteristics of participants by food security status

\begin{tabular}{|c|c|c|c|}
\hline & $\begin{array}{l}\text { Food secure } \\
n=218(58 \%) \\
n(\%)\end{array}$ & $\begin{array}{l}\text { Food insecure } \\
n=158(42 \%) \\
n(\%)\end{array}$ & $p$ value* \\
\hline \multicolumn{4}{|l|}{ Age } \\
\hline $18-24$ years & $84(57.5)$ & $62(42.5)$ & 0.056 \\
\hline $25-29$ years & $70(61.4)$ & $44(38.6)$ & \\
\hline $30-35$ years & $45(52.3)$ & $41(47.7)$ & \\
\hline$>35$ years & $19(63.3)$ & $11(36.7)$ & \\
\hline \multicolumn{4}{|l|}{ Population group } \\
\hline Black & $72(54.1)$ & $61(45.9)$ & 0.164 \\
\hline Coloured & $134(59.8)$ & $90(40.2)$ & \\
\hline White & $5(100)$ & 0 & \\
\hline Indian & $7(50.0)$ & $7(50.0)$ & \\
\hline \multicolumn{4}{|l|}{ Spoken language } \\
\hline English & $90(64.8)$ & $49(35.2)$ & 0.104 \\
\hline Afrikaans & $63(52.1)$ & $58(47.9)$ & \\
\hline isiXhosa & $65(56.0)$ & $51(44.0)$ & \\
\hline \multicolumn{4}{|l|}{ Gravidity } \\
\hline 1st Pregnancy & $62(64.6)$ & $34(35.4)$ & 0.005 \\
\hline 2-4 Pregnancies & $144(59.0)$ & $100(41.0)$ & \\
\hline$>4$ Pregnancies & $12(33.3)$ & $24(66.7)$ & \\
\hline \multicolumn{4}{|l|}{ Parity } \\
\hline No previous births & $79(64.7)$ & $43(35.3)$ & $<0.001$ \\
\hline 1 Previous birth & $71(55.5)$ & $57(44.5)$ & \\
\hline 2 Previous births & $55(66.3)$ & $28(33.7)$ & \\
\hline$>3$ Previous births & $13(30.2)$ & $30(69.8)$ & \\
\hline \multicolumn{4}{|l|}{ Highest standard passed } \\
\hline Grade $2-7$ & $11(52.4)$ & $10(47.6)$ & 0.021 \\
\hline Grade $8-9$ & $26(42.6)$ & $35(57.4)$ & \\
\hline Grade $10-12$ & $181(61.6)$ & $113(38.4)$ & \\
\hline \multicolumn{4}{|l|}{ Employment status } \\
\hline Employed & $115(68.5)$ & $53(31.5)$ & $<0.001$ \\
\hline Unemployed & $103(49.5)$ & $105(50.5)$ & \\
\hline \multicolumn{4}{|c|}{ Household income (monthly) } \\
\hline R0-R500 & $3(75.0)$ & $1(25.0)$ & 0.049 \\
\hline R501-R1000 & $2(33.3)$ & $4(6.7)$ & \\
\hline R1001-R2000 & $16(39.0)$ & $25(61.0)$ & \\
\hline R2001-R5000 & $50(54.4)$ & $42(45.6)$ & \\
\hline$>\mathrm{R} 5000$ & $42(67.7)$ & $20(32.3)$ & \\
\hline \multicolumn{4}{|l|}{ Asset index } \\
\hline Poorest & $46(48.9)$ & $48(51.1)$ & 0.023 \\
\hline Very poor & $49(52.1)$ & $45(47.9)$ & \\
\hline Poor & $61(63.5)$ & $35(36.5)$ & \\
\hline Least poor & $62(68.1)$ & $29(31.9)$ & \\
\hline \multicolumn{4}{|l|}{ Relationship type } \\
\hline Married/stable partner & $198(58.6)$ & $140(41.4)$ & 0.726 \\
\hline Casual/no partner & $20(55.6)$ & $16(44.4)$ & \\
\hline \multicolumn{4}{|l|}{ Cohabiting with partner } \\
\hline Yes & $126(60.3)$ & $83(39.7)$ & 0.647 \\
\hline Sometimes & $24(54.5)$ & $20(45.5)$ & \\
\hline No & $54(55.7)$ & $43(44.3)$ & \\
\hline
\end{tabular}


Table 1 (continued)

\begin{tabular}{lllr}
\hline & $\begin{array}{l}\text { Food secure } \\
n=218(58 \%)\end{array}$ & $\begin{array}{l}\text { Food insecure } \\
n=158(42 \%)\end{array}$ & $p$ value* \\
& $n(\%)$ & $n(\%)$ & \\
\hline HIV status: positive & $24(58.5)$ & $17(41.5)$ & 0.961 \\
Planned pregnancy & $88(64.2)$ & $49(35.8)$ & 0.064 \\
History of mental illness & $22(38.6)$ & $35(61.4)$ & 0.001 \\
Experience of a threatening life event & $61(41.8)$ & $85(58.2)$ & $<0.001$ \\
Experience of intimate partner violence & $22(37.9)$ & $36(62.1)$ & 0.001 \\
\hline
\end{tabular}

*Chi-square test

Table 2 Household food security questions

\begin{tabular}{l}
\hline Questions \\
\hline $\begin{array}{l}\text { Households where the food that was bought in the last } 6 \text { months sometimes/often did not last, and there was not any money to buy } \\
\text { more }\end{array}$ \\
Households where, in the last 6 months, members often/sometimes could not afford to eat balanced meals \\
Households where, in the last 6 months, members ever had to cut down on the size of meals or skip meals because there was not \\
enough money for food \\
Households where, in the last 6 months, members often cut down on the size of meals or skip meals because there was not enough \\
money for food \\
Households where, in the last 6 months, members ever ate less than they felt they should because there was not enough money for \\
food \\
Households where, in the last 6 months, members were ever hungry but did not eat because there was not enough money for food
\end{tabular}

Table 3 Bivariate associations between food security status and MINI-diagnosed disorders

\begin{tabular}{lrlr}
\hline & $\begin{array}{l}\text { Food } \\
\text { secure } \\
(n=218) \\
n(\%)\end{array}$ & $\begin{array}{l}\text { Food } \\
\text { insecure } \\
(n=158)\end{array}$ & $p$ value* \\
& $n(\%)$ & \\
\hline $\begin{array}{l}\text { Major depressive episode } \\
\quad \text { MDE) }\end{array}$ & $27(33.3)$ & $54(66.7)$ & $<0.001$ \\
Any anxiety disorder & $35(40.7)$ & $51(59.3)$ & $<0.001$ \\
Suicidal ideation & $28(59.6)$ & $19(40.4)$ & 0.813 \\
Suicidal behaviour & $8(33.3)$ & $16(66.7)$ & 0.011 \\
Alcohol dependence & $21(42.9)$ & $28(57.1)$ & 0.021 \\
Substance dependence & $5(33.3)$ & $10(66.7)$ & 0.048 \\
\hline
\end{tabular}

${ }^{*}$ Chi-square test

Pellowski et al. used a sample of pregnant women with children, while Dewing et al. used a sample of postnatal women.

Our findings show that suicidal behaviour increases the odds of being food insecure by more than five times. While these results are similar to those of another South African study [29], our increased odds are far greater than the $12 \%$ increased risk previously reported. Furthermore, the relationship between food insecurity and suicidality appears to be bidirectional, with a study using a sample of non-pregnant adult women in India [45] and another using a sample of HIV positive adults in Uganda [46] showing that being food insecure increases the risk of suicidal thoughts and behaviour. Theories to explain the link include biological mechanisms whereby micronutrient deficiency and malnutrition have a negative impact on mental health, and psychological mechanisms whereby stress, extreme worry and anxiety cause maladaptive responses such as impaired thought processes, decision making and concentration, leading to suicidal ideation and behaviour [47]. As with other mental illnesses, suicidal behaviour may lead to increased health expenses, unemployment, social withdrawal and the inability to plan ahead, resulting in reduced ability to generate income or provide adequate amounts of food for the family [44].

Although many of the associations confirmed findings in the literature there was an exception. We found that having an anxiety disorder did not increase the odds of being food insecure. These results are unanticipated as food security is thought to cause uncertainty in the household, leading to feelings of stress that in turn lead to symptoms of anxiety and depression [48].

When examining the factors associated with depression, we found that the risk of depression increased fivefold with food insecurity or anxiety disorder. As we adjusted for household income (a proxy for poverty) in the multivariate regression model, we can conclude that the effect of food insecurity on MDE is independent of the effect of income. Similar findings have been reported before. Tsai et al. [15], using a longitudinal sample of pregnant South 
Table 4 Odds ratios for food insecurity using logistic regression

\begin{tabular}{llrrr}
\hline & Univariate & & \multicolumn{2}{l}{ Multivariate } \\
\cline { 5 - 5 } & OR* (95\% CI) & $p$ value & OR* (95\% CI) & $p$ value \\
\hline Participant income <R2000/month [ref: income > R2000/month] & $1.96(1.23-3.12)$ & 0.004 & $1.48(0.60-3.61)$ & 0.394 \\
Unemployment [ref: employed] & $2.21(1.44-3.40)$ & $<0.001$ & $1.17(0.51-2.69)$ & 0.706 \\
Household income <R2000/month [ref: income > R2000/month] & $0.73(0.53-0.99)$ & 0.041 & $1.57(0.67-3.66)$ & 0.300 \\
1 child [ref: no children] & $1.16(0.76-1.80)$ & 0.479 & $1.43(0.57-3.60)$ & 0.444 \\
2 children [ref: no children] & $0.64(0.38-1.06)$ & 0.085 & $0.91(0.34-2.43)$ & 0.859 \\
3 or more children [ref: no children] & $3.70(1.86-7.35)$ & $<0.001$ & $3.79(1.25-11.55)$ & 0.019 \\
Suicidal behaviour [ref: no suicidal behaviour] & $2.96(1.23-7.10)$ & 0.015 & $5.34(1.26-22.57)$ & 0.023 \\
Major depressive episode (MDE) [ref: no MDE episode] & $3.67(2.18-6.18)$ & $<0.001$ & $4.27(1.43-12.70)$ & 0.009 \\
Anxiety disorder [ref: no anxiety disorder] & $2.49(1.52-4.08)$ & $<0.001$ & $1.13(0.48-2.60)$ & 0.779 \\
History of mental illness [ref: no previous mental illness] & $2.53(1.42-4.52)$ & 0.002 & $1.52(0.59-3.91)$ & 0.380 \\
Threatening life event [ref: no threatening life events] & $1.97(1.30-3.01)$ & 0.001 & $1.49(0.75-2.97)$ & 0.356 \\
Intimate partner violence (IPV) [ref: no IPV] & $2.63(1.48-4.68)$ & 0.001 & $1.26(0.41-3.87)$ & 0.685 \\
Perceived social support [ref: minimal perceived social support] & $0.97(0.95-0.99)$ & 0.002 & $0.98(0.96-1.01)$ & 0.277 \\
Substance dependence [ref: no substance dependence] & $3.40(1.36-8.47)$ & 0.009 & $1.57(0.14-17.72)$ & 0.716 \\
Alcohol dependence [ref: not alcohol dependent] & $2.02(1.10-3.71)$ & 0.023 & $1.36(0.47-3.98)$ & 0.571 \\
\hline
\end{tabular}

*Odds ratio

Table 5 Odds ratios for MDE using logistic regression

\begin{tabular}{|c|c|c|c|c|}
\hline & \multicolumn{2}{|l|}{ Univariate } & \multicolumn{2}{|l|}{ Multivariate } \\
\hline & $\mathrm{OR} *(95 \% \mathrm{CI})$ & $p$ value & $\mathrm{OR} *(95 \% \mathrm{CI})$ & $p$ value \\
\hline Household income < R2000/month [ref: income $>$ R2000/month] & $1.67(0.76-3.64)$ & 0.199 & $1.26(0.42-3.71)$ & 0.681 \\
\hline 1 Child [ref: no children] & $0.78(0.46-1.33)$ & 0.364 & $1.08(0.22-5.39)$ & 0.926 \\
\hline 2 Children [ref: no children] & $0.62(0.32-1.19)$ & 0.150 & $0.84(0.15-4.73)$ & 0.844 \\
\hline 3 or more children [ref: no children] & $2.86(1.48-5.51)$ & 0.002 & $1.75(0.31-9.96)$ & 0.529 \\
\hline Unplanned pregnancy [ref: planned pregnancy] & $0.42(0.23-0.74)$ & 0.003 & $0.46(0.14-1.53)$ & 0.208 \\
\hline Happy about pregnancy [ref: unhappy about pregnancy] & $1.91(1.09-3.31)$ & 0.023 & $0.99(0.29-3.37)$ & 0.988 \\
\hline Substance dependence [ref: no substance dependence] & $4.52(1.91-10.68)$ & 0.001 & $15.83(1.31-191.48)$ & 0.030 \\
\hline Anxiety disorder [ref: no anxiety] & $7.80(4.51-13.51)$ & $<0.001$ & $5.04(1.71-14.82)$ & 0.003 \\
\hline Food Insecurity [ref: food secure] & $3.67(2.18-6.18)$ & $<0.001$ & $5.30(1.63-17.30)$ & 0.006 \\
\hline Intimate partner violence (IPV) [ref: no IPV] & $2.94(1.62-5.36)$ & $<0.001$ & $2.76(0.84-9.11)$ & 0.096 \\
\hline Perceived social support [ref: poor social support] & $0.95(0.93-0.97)$ & $<0.001$ & $0.95(0.92-0.98)$ & 0.003 \\
\hline Threatening life event [ref: no threatening life events] & $4.79(2.81-8.15)$ & $<0.001$ & $1.62(0.60-4.44)$ & 0.343 \\
\hline Suicidal thoughts and behaviour (SIB) [ref: no SIB] & $2.16(1.21-3.85)$ & 0.009 & $1.66(0.55-5.03)$ & 0.369 \\
\hline History of mental illness [ref: no previous mental illness] & $5.84(3.20-10.64)$ & $<0.001$ & $1.96(0.63-6.17)$ & 0.247 \\
\hline Alcohol dependence [ref: not alcohol dependent] & $1.97(1.02-3.79)$ & 0.043 & $0.61(0.14-2.63)$ & 0.505 \\
\hline
\end{tabular}

*Odds ratio

African women and adjusting for a number of extraneous variables including an asset wealth index which was used as a proxy for poverty, reported a dose-response relationship between food insecurity and greater depression symptom severity. However, in this large study, food insecurity was measured using a single-item question that referred to the number of days in the past week that the participant had gone hungry, whereas our study measured household food insecurity over the previous 6 months. Studies in urban [14] and rural [19] areas of Ethiopia reported that being pregnant and experiencing household food insecurity increased the risk of depression by more than four times.

Our findings suggest that the theory that common mental illnesses and poverty interact in a negative cycle [49, $50]$, can be extended to food insecurity and common mental 
illnesses. There are a number of potential explanations for the strong association observed between food insecurity and depression among the pregnant women in our study. Household food insecurity, especially in pregnant women may cause feelings of shame and desperation $[48,51]$, which result in decreased social engagement [52, 53], increased anxiety and distress, risk-taking behaviour, impulsivity, aggression [54], dysfunctional relationships, nutritional deficiencies, and symptoms of depression [54]. Conversely, mothers and prospective mothers who are depressed, may be at increased risk of remaining in poverty and being food insecure as a result of increased health expenditure, stigma [55], social withdrawal, lost work opportunities, risky behaviour, decreased earnings, and impaired ability to plan ahead $[44,56]$.

We found that the odds of MDE were 15 times greater in women who were substance dependent. This study confirms previous findings of a strong association between depression and substance dependence. In a systematic review by Lai et al. [57], all of the 18 studies used in the meta-analysis reported significant associations between drug abuse/ dependence and depression. Similarly, Vythilingum et al. [58], reported a significant association between depression and substance use in a sample of pregnant South African women.

A strength of our study, in relation to previous work in this area, is the use of the MINI Plus assessment tool to diagnose depression, anxiety, alcohol and drug dependence and to assess for suicidal ideation and behaviour. In addition, the data collection was supervised by a clinical psychologist which strengthens the accuracy of the data. However, there are several limitations which need to be acknowledged. We do not have demographic information on 48 women who did not complete the questionnaires. We assessed food insecurity at a household level. As two-thirds of the participants had other children, intra-household food allocation would likely have favoured the children. It's possible that the high levels of food insecurity reported by the mothers referred to their individual level of food insecurity, rather than accurately representing the household level. We used a shortened version of the HFSSM, which is only one of many tools used to measure food insecurity, making it difficult to compare our results to other studies. Furthermore, we used cut-points for the HFSSM developed in the US, which have not been validated in a South African population. The study design was cross-sectional, making it impossible to determine whether food insecurity preceded the mental illness, or the mental illness preceded food insecurity.

Further research is needed to improve our understanding of the relationships identified in this study and to determine the directions of causality. Intervention studies, using a randomised control study design, that combine poverty alleviation measures, such as food parcels or food vouchers with mental health interventions are needed. These studies would be most effective if they collect both qualitative and quantitative data.

Pregnancy is a particularly vulnerable time for women, as their income earning potential is decreased and their health and childcare needs are increased. Providing financial support to women during the perinatal period in the form of a pregnancy grant, as well as free and easily accessible mental health care is essential if we want to improve the health of mothers and their children.

\section{Conclusion}

Our study provides important evidence of the strong associations between food insecurity, maternal depression and suicidality in low-income pregnant women in Cape Town. Longitudinal and qualitative data are required to assess potential causal relationships within these complex associations. Interventions aimed at alleviating food insecurity in pregnant women and new mothers are likely to benefit both their physical and mental well-being, thereby decreasing the growing burden of disease attributed to common mental illnesses.

Acknowledgements CL is supported by the Programme for Improving Mental health carE (PRIME), funded by the UK Department for International Development. The views expressed in this article do not necessarily reflect the views of the UK government. The funders played no role in the analysis of the data or in the decision to publish. The authors wish to acknowledge and thank the staff and study participants at the Hanover Park Midwife Obstetric Unit, as well as Prof. Susan Fawcus, Liesl Hermanus, Sheily Ndwayana, Michael Onah and Thandi van Heyningen for their assistance. We would also like to thank the philanthropic organisations that provide general support funding to the Perinatal Mental Health Project.

\section{Compliance with ethical standards}

Conflict of interest On behalf of all authors, the corresponding author states that there is no conflict of interest.

Ethical statement This study was approved by the University of Cape Town Human Research Ethics Committee (HREC REF: 131/ 2009). Study participants were 18 years and older, and written informed consent was sought before data collection.

Open Access This article is distributed under the terms of the Creative Commons Attribution 4.0 International License (http://creativeco mmons.org/licenses/by/4.0/), which permits unrestricted use, distribution, and reproduction in any medium, provided you give appropriate credit to the original author(s) and the source, provide a link to the Creative Commons license, and indicate if changes were made. 


\section{References}

1. Statistics South Africa (2016) Community Survey 2016. http:// cs2016.statssa.gov.za/wp-content/uploads/2016/07/NT-30-062016-RELEASE-for-CS-2016-_Statistical-releas_1-July-2016. pdf. Accessed 21 July 2017

2. Statistics South Africa (2017) Poverty trends in South Africa: An examination of absolute poverty between 2006 and 2015. http:// www.statssa.gov.za/publications/Report-03-10-06/Report-03-10062015.pdf. Accessed 4 November 2017

3. Food and Agriculture Organisation of the United States (2001) The state of food insecurity in the world 2001. http://www.fao. org/3/a-y1500e.pdf. Accessed 4 November 2017

4. Blumberg SJ, Bialostosky K, Hamilton WL, Briefel RR (1999) The effectiveness of a short form of the Household Food Security Scale. Am J Public Health 89(8):1231-1234

5. Chersich M, Blaauw D, Scorgie F et al (2016) Safeguarding maternal and child health in South Africa by starting the Child Support Grant before birth: design lessons from pregnancy support programmes in 27 countries. SA Med J 106(12):1192-1210

6. Tomlinson M, Swartz L, Kruger L, Gureje O (2007) Manifestations of affective disturbance in sub-Saharan Africa: key themes. J Affect Disord 102(1):191-198

7. Hamad R, Fernald LC, Karlan DS, Zinman J (2008) Social and economic correlates of depressive symptoms and perceived stress in South African adults. J Epidemiol Community Health 62(6):538-544

8. Fisher J, de Mello M, Patel V et al (2012) Prevalence and determinants of common perinatal mental disorders in women in low-and lower-middle-income countries: a systematic review. Bull World Health Organ 90(2):139-149

9. Rochat TJ, Richter LM, Doll HA et al (2006) Depression among pregnant rural South African women undergoing HIV testing. J Am Med Assoc 295(12):1373-1378

10. Rochat TJ, Tomlinson M, Bärnighausen T, Newell M, Stein A (2011) The prevalence and clinical presentation of antenatal depression in rural South Africa. J Affect Disord 135(1):362-373

11. Hanlon C, Medhin G, Alem A et al (2009) Impact of antenatal common mental disorders upon perinatal outcomes in Ethiopia: the P-MaMiE population-based cohort study. Trop Med Int Health 14(2):156-166

12. Pryor L, Lioret S, van der Waerden J et al (2016) Food insecurity and mental health problems among a community sample of young adults. Soc Psychiatry Psychiatr Epidemiol 51(8):1073-1081

13. Garcia J, Hromi-Fiedler A, Mazur RE et al (2013) Persistent household food insecurity, HIV, and maternal stress in peri-urban Ghana. BMC Public Health 13(1):215

14. Jebena MG, Taha M, Nakajima M et al (2015) Household food insecurity and mental distress among pregnant women in Southwestern Ethiopia: a cross sectional study design. BMC Pregnancy Childbirth 15(1):250

15. Tsai AC, Tomlinson M, Comulada WS, Rotheram-Borus MJ (2016) Food insufficiency, depression, and the modifying role of social support: Evidence from a population-based, prospective cohort of pregnant women in peri-urban South Africa. Soc Sci Med 151:69-77

16. Melchior M, Caspi A, Howard LM et al (2009) Mental health context of food insecurity: a representative cohort of families with young children. Pediatr 124(4):e564-e572

17. Patel V (2001) Poverty, inequality, and mental health in developing countries. In: Leon D, Walt G (eds) Poverty, inequality, and health: an international perspective. Oxford University Press, England, 247-262
18. Patel V, Kleinman A (2003) Poverty and common mental disorders in developing countries. Bull World Health Organ 81(8):609-615

19. Dibaba Y, Fantahun M, Hindin MJ (2013) The association of unwanted pregnancy and social support with depressive symptoms in pregnancy: evidence from rural Southwestern Ethiopia. BMC Pregnancy Childbirth 13(1):135

20. Hromi-Fiedler A, Bermúdez-Millán A, Segura-Pérez S, PérezEscamilla R (2011) Household food insecurity is associated with depressive symptoms among low-income pregnant Latinas. Matern Child Nutr 7(4):421-430

21. Huddleston-Casas C, Charnigo R, Simmons LA (2009) Food insecurity and maternal depression in rural, low-income families: a longitudinal investigation. Public Health Nutr 12(8):1133-1140

22. Du Toit NFB (2014) Gangsterism on the Cape Flats: a challenge to 'engage the powers'. HTS Theol Stud 70(3):01-07

23. City of Cape Town. Hanover Park-a public investment framework (2015) http://resource.capetown.gov.za/documentcentre/ Documents/City\%20strategies,\%20plans\%20and\%20framewor ks/Hanover\%20Park\%20Public\%20Investment\%20Framewor k_22\%20October\%202015.pdf. Accessed 5 December 2017

24. Zimet GD, Dahlem NW, Zimet SG, Farley GK (1988) The multidimensional scale of perceived social support. J Pers Assess 52(1):30-41

25. Brugha TS, Cragg D (1990) The list of threatening experiences: the reliability and validity of a brief life events questionnaire. Acta Psychiatr Scand 82(1):77-81

26. Straus MA, Hamby SL, Boney-McCoy S, Sugarman DB (1996) The revised conflict tactics scales (CTS2) development and preliminary psychometric data. J Fam Issues 17(3):283-316

27. Sheehan D, Lecrubier Y, Sheehan KH et al (1998) Diagnostic psychiatric interview for DSM-IV and ICD-10. J Clin Psychiatr 59:22-33

28. Lecrubier Y, Sheehan DV, Weiller E et al (1997) The Mini International Neuropsychiatric Interview (MINI). A short diagnostic structured interview: reliability and validity according to the CIDI. Eur Psychiatry 12(5):224-231

29. Dewing S, Tomlinson M, le Roux IM, Chopra M, Tsai AC (2013) Food insecurity and its association with co-occurring postnatal depression, hazardous drinking, and suicidality among women in peri-urban South Africa. J Affect Disord 150(2):460-465

30. Myer L, Smit J, Roux LL, Parker S, Stein DJ, Seedat S (2008) Common mental disorders among HIV-infected individuals in South Africa: prevalence, predictors, and validation of brief psychiatric rating scales. AIDS Patient Care STDS 22(2):147-158

31. Lecrubier Y, Sheehan D, Hergueta T, Weiller E (1998) The mini international neuropsychiatric interview. Eur Psychiatry 13(1004): 198

32. Baron EC, Davies T, Lund C (2017) Validation of the 10-item Centre for Epidemiological Studies Depression Scale (CES-D-10) in Zulu, Xhosa and Afrikaans populations in South Africa. BMC Psychiatry 17(1):6

33. Van Heyningen T, Myer L, Onah M, Tomlinson M, Field S, Honikman S (2016) Antenatal depression and adversity in urban South Africa. J Affect Disord 203:121-129

34. Deaton A (1997) The analysis of household surveys: a microeconometric approach to development policy. Washington, D.C.: The World Bank. http://documents.worldbank.org/curated/ en/593871468777303124/The-analysis-of-household-surveys-amicroeconometric-approach-to-development-policy. Accessed on 14 October 2017

35. Booysen F, Van Der Berg S, Burger R, Von Maltitz M, Du Rand $G$ (2008) Using an asset index to assess trends in poverty in seven Sub-Saharan African countries. World Dev 36(6):1113-1130

36. Harttgen K, Klasen S, Vollmer S (2013) An African growth miracle? Or: what do asset indices tell us about trends in economic performance? Rev Income Wealth 59:S1 
37. United States Department of Agriculture (2012) Six-item short form of the food security module. https://www.ers.usda.gov/topic s/food-nutrition-assistance/food-security-in-the-us/survey-tools/. Accessed 11 October 2017

38. Western Cape Government (2013) Report on the identification of policing needs and priorities in the Western Cape. https:// www.westerncape.gov.za/assets/departments/community-safety/ pnps_2012-2013_report_29-08-2013.pdf. Accessed 16 October 2017

39. Wight V, Kaushal N, Waldfogel J, Garfinkel I (2014) Understanding the link between poverty and food insecurity among children: Does the definition of poverty matter? J Child Poverty 20(1):1-20

40. Food and Agriculture Organisation (2008) An introduction to the basic concepts of food insecurity. http://www.fao.org/docrep/013/ al936e/al936e00.pdf. Accessed 16 October 2017

41. Lund C, Breen A, Flisher AJ et al (2010) Poverty and common mental disorders in low and middle income countries: a systematic review. Soc Sci Med 71(3):517-528

42. Weigel MM, Armijos RX, Racines M, Cevallos W, Castro NP (2016) Association of household food insecurity with the mental and physical health of low-income urban Ecuadorian women with children. J Environ Public Health. https://doi. org/10.1155/2016/5256084

43. Chung H, Kim OY, Kwak SY, Cho Y, Lee KW, Shin M (2016) Household food insecurity is associated with adverse mental health indicators and lower quality of life among Koreans: results from the Korea National Health and Nutrition Examination Survey 2012-2013. Nutrients 8(12):819

44. Pellowski JA, Barnett W, Kuo CC, Koen N, Zar HJ, Stein DJ (2017) Investigating tangible and mental resources as predictors of perceived household food insecurity during pregnancy among women in a South African birth cohort study. Soc Sci Med 187:76-84

45. Maselko J, Patel V (2008) Why women attempt suicide: the role of mental illness and social disadvantage in a community cohort study in India. J Epidemiol Community Health 62(9):817-822

46. Kinyanda E, Hoskins S, Nakku J, Nawaz S, Patel V (2012) The prevalence and characteristics of suicidality in HIV/AIDS as seen in an African population in Entebbe district, Uganda. BMC Psychiatry 12(1):63
47. Davison KM, Marshall-Fabien GL, Tecson A (2015) Association of moderate and severe food insecurity with suicidal ideation in adults: national survey data from three Canadian provinces. Soc Psychiatry Psychiatr Epidemiol 50(6):963-972

48. Weaver LJ, Hadley C (2009) Moving beyond hunger and nutrition: a systematic review of the evidence linking food insecurity and mental health in developing countries. Ecol Food Nutr 48(4):263-284

49. The World Health Organisation (2010) Mental disorders: equity and social determinants. http://www.who.int/social_determinants/ tools/EquitySDandPH_eng.pdf\#page=125. Accessed 14 October 2017

50. Lund C, De Silva M, Plagerson S et al (2011) Poverty and mental disorders: breaking the cycle in low-income and middle-income countries. Lancet 378(9801):1502-1514

51. Hamelin A, Beaudry M, Habicht J (2002) Characterization of household food insecurity in Quebec: food and feelings. Soc Sci Med 54(1):119-132

52. Hamelin AM, Habicht JP, Beaudry M (1999) Food insecurity: consequences for the household and broader social implications. J Nutr 129(2S):525S-528S

53. Tarasuk VS (2001) Household food insecurity with hunger is associated with women's food intakes, health and household circumstances. J Nutr 131(10):2670-2676

54. Nettle D (2017) Does hunger contribute to socioeconomic gradients in behavior? Front Psychol 8:358

55. Pyne JM, Kuc EJ, Schroeder PJ, Fortney JC, Edlund M, Sullivan G (2004) Relationship between perceived stigma and depression severity. J Nerv Ment Dis 192(4):278-283

56. Haushofer J, Fehr E (2014) On the psychology of poverty. Sci 344(6186):862-867

57. Lai HM, Cleary M, Sitharthan T, Hunt GE (2015) Prevalence of comorbid substance use, anxiety and mood disorders in epidemiological surveys, 1990-2014: a systematic review and metaanalysis. Drug Alcohol Depend 154:1-13

58. Vythilingum B, Roos A, Faure SC, Geerts L, Stein DJ (2012) Risk factors for substance use in pregnant women in South Africa. SA Med J 102(11):853-854 